\title{
Development and application of life cycle assessment in China over the last decade
}

\author{
Zuoren Nie
}

Received: 25 April 2013 / Accepted: 26 April 2013 /Published online: 26 July 2013

(C) Springer-Verlag Berlin Heidelberg 2013

\section{Introduction}

The first article published in the International Journal of LCA on life cycle assessment (LCA) research in China dates back to 2001 (Nie et al. 2001), when LCA research and application was first initiated there. Now, more than 10 years later, there has been remarkable progress with many publications on different subjects. Current research in China covers a lot of areas including regional life cycle impact assessment (LCIA) methodology of abiotic resources (Gao et al. 2009a, b, c), land use (Liu et al. 2010), the Chinese life cycle inventory (LCI) database (Gong et al. 2006), as well as typical case studies such as power generation (Di et al. 2007), iron and steel (Li et al. 2002), magnesium (Gao et al. 2009a, b, c), construction (Wu et al. 2012), continuous pad-dyeing technology for cotton fabrics (Yuan et al. 2013), aseptic packaging waste management (Xie et al. 2013), desktop personal computers (PCs) (Song et al. 2013), polymers (Hong and Li 2012), titanium (Liao et al. 2012), and so on. In addition, a symposium focused on materials LCA (MLCA) and ecomaterials has been held biennially in China as part of the IUMRS international conference on advanced materials.

In addition, many national projects were initiated in recent years to support LCA practice and related research. Especially, the first MLCA research was sponsored by the National Hightech Research and Development (R\&D) program (863 Program) in 1998. This program aimed to develop regional MLCA methods suitable for the Chinese situation, by performing case studies on manufacturing technologies and processes of typical materials involving steel and iron, aluminum, cement, ceramic, polymers, and construction coatings. In

\section{Z. Nie $(\square)$}

College of materials science and engineering, Beijing University of Technology (BJUT), Chaoyang District Beijing 100124, People's Republic of China

e-mail: zrnie@bjut.edu.cn
2001, MLCA research was continuously supported by the 863 Program to develop the MLCA database and relevant analysis software. Moreover, after 2006, more and more national R\&D programs enhanced LCA research in different areas. The Chinese national standards on LCA, GB/T 24040-2008 and GB/T 24044-2008 (translated from the ISO 14040:2006 and ISO 14044:2006 standards), were also revised and issued.

In 2007, the Green Design theory and methodology, and its key technology based on product life cycle assessment and design for disassembly/recycling, were also supported by the National Key Technology R\&D Program. The Green Design oriented life cycle assessment system seamlessly combined a modularized product disassembly/recycling analysis tool and a product-based environmental impact assessment system.

The China Certification and Accreditation Administration started a project called "research on typical products, LCA analysis, and type III environmental label authentication technology in paper making industry" in 2008. Life cycle thinking and methodology were introduced to set up the assessment index system for type III environmental labels verification in the Chinese papermaking industry.

The project "key industries for energy saving and emissions reduction technology assessment and application" supported by the ministry of industry and technology information was carried out in 2010. The project covered 11 key industries such as metal and nonmetal materials, petrochemicals, automobiles, electronics, and information. It made notable progress in the qualitative and quantitative methodology based on the whole life cycle of products. Based on the application of life cycle methodology in the 11 industries, a catalog, guidance manual, and cases for industrial advanced technology for energy saving and emissions reduction were completed. The project "environmental loading quantitative assessment technology and application on material processes" completed by Beijing University of Technology (BJUT) was given the National Science and Technology Progress Award of China in 2012. 
The great support received from the government and academic institutions allowed the research and application of LCA to make great progress in recent years. LCA is considered to be one of the most important tools to analyze and improve environmental performance of materials and products, providing technical and decision making support in many areas (e.g., achieve energy-saving and emissionreducing targets). This article summarizes the current status and scope of LCA activities in relation to some of the progress as well as weaknesses in LCA research presented in China. Thanks are given to those who contributed; apologies are offered to any individuals, organizations, or projects that may be overlooked.

\section{Research on LCA methodology in China}

So far, the development of the methodology and the benchmark system of LCA has already attracted much attention of Chinese LCA researchers. Some are focusing on developing regional characteristic indicators, sustainability indicators, and data quality analysis. However, there is still not a widely accepted standard, and the development of LCA methodology is still in progress.

\subsection{Research on regional LCIA methodology}

Gao et al. (2009a, b, c) proposed a regional LCIA model for abiotic resource depletion in China and calculated the characteristic factors of 14 types of metals, 26 types of nonmetals, and 3 types of energy resources based on Chinese characters in mineral resources and the statistical features in the elementary data, all of which play important roles for the Chinese national economy. And a case study on primary magnesium production was performed to compare LCIA results of abiotic resources between current global LCIA factors and new Chinese factors.

Liu et al. (2010) established a model with Chinese characterization factors for quantifying the damages to ecosystems by land use activity in the framework of LCA. In this method, the land use elementary flows and parameters were linked to the impact indicators, and the characterization formulas of the two forms of land utilization were derived, respectively, according to the ecological theory. Moreover, based on this method, the characterization factors of both land occupation and land transformation were calculated using Chinese empirical data, which can be incorporated into an LCA framework and applied to a Chinese LCA case study.

\subsection{Research on data quality analysis methodology}

High quality data is important in carrying out LCAs. Data reliability directly influences the capability of the results and its application. Based on the analysis of the main character of pedigree matrix modeling and stochastic modeling, an integrated model of data quality was established by the expected value method to calculate the whole data quality index. The transformation from deterministic to stochastic LCA modeling was also developed, and an LCI stochastic model was established for a case study of eco-cement production (Gong 2006).

Regarding data deficiency in MLCA research in China, missing data were predicted and calculated based on information available in LCIs by using three methods: complete case analysis, linear regression analysis, and Markov Chain Monte Carlo analysis. Moreover, an analysis of the advantages, disadvantages, and scope of application of these three methods was performed. A data quality analysis system to reduce the interference from the missing data was established (Liu et al. 2009).

\subsection{Research on LCA methodology in China needs} to be improved continuously

Although LCA methodology in China has developed and somewhat matured during the last decades, its scientific implication still needs to be improved and enriched, mainly in the following areas:

- In accordance with the requirements for consistency and comparability, the depth and breadth of simulating environment mechanisms need to be increased. The correlation between characterization results and the environment needs to be further proved, so as to enable the potential environmental impact assessment results to facilitate integrated decision making.

- Regional LCIA methodology and related characterization factors need to be improved to support LCA case studies; moreover, differences in environmental impacts caused by spatial and temporal differentiation need to be identified.

- Uncertainty analysis needs to be established to improve the application scope and result interpretation for decision making.

- Related disciplines need to be further developed to improve the method for comparing various impact categories, such as resource depletion, human health, land use, water use, and so on, thereby providing better support for integrated decision making.

\section{Development of the Chinese LCA Database}

It is well-known that LCA is very data intensive; collecting LCI data may be the most time and effort consuming phase of LCA practice. In order to facilitate this work and to avoid 
duplication in data compilation, many databases have been developed in the last decade around the world and also in China. With the support of the National 863 Program, environmental burden data of main materials and products were collected and processed. From these data, the MLCA database (named sinocenter) and related software were developed. As a result of the exploration and development within recent years, a research and consultation platform of MLCA was established at the BJUT. Most database systems are based on unit process data representing specific technologies of Chinese materials industry, which can provide the possibility for choosing the appropriate technologies in the case investigated, and allowing the LCA practitioner to review underlying details of the process data and methodological choices for a product or service environmental assessment. Up to now, the practice of MLCA in China has attracted attention from several international LCA institutions. The research center has widely cooperated with ISO and PRé Consultants and participated in the establishment of a global LCA union. Presently, more than 100,000 records are incorporated in the sinocenter database. The concrete classification includes the following:

- Power supply: thermal power, hydropower, and nuclear power;

- Primary energy: raw coal, crude oil, and natural gas;

- Secondary energy: fuel oil, gasoline, diesel, coal, and gas;

- Transportation: pipeline, road, shipping, and railway transportation;

- Mineral resources: ferrous metal, nonferrous metals, and inorganic nonmetals;

- Materials: ferrous metal materials (steel, aluminum, magnesium, etc.), building materials (cement, glass, ceramic, coating, floor coiled material, adhesives, wood-based panel, etc.), chemical materials (Ethylene, PVC, PP, ABS, etc.), connecting material (solder, etc.);

- Standards: steel, cement, etc.

Facing an increasing demand for LCI data and fast development in China, the LCA database needs to be improved continuously in the following areas:

- Expansion and improvement of current LCA datasets to meet the need of LCA case study of different products in China;

- Continual updates due to frequent technological innovations in China;

- Establishment of data quality analysis standards to describe and identify the representativeness and reliability of the LCI datasets;

- LCIs need be divided at the regional level because there is often a big spatial difference in materials production and other processes such as power supply in China.

\section{Case studies}

There are many typical examples from industry, consultants, and academia which use LCA methods to choose, optimize, and design technique processes, such as energy supply as well as the production and manufacturing of products.

\subsection{LCA in the energy industry}

The LCI of primary and major secondary energy production is fundamental for the LCA database and to carry out LCA case studies for all products. In recent years, the Chinese fundamental energy inventories have been developed and already been applied in the LCA case study of materials and other products in China, as well as in international comparative studies. Di et al. (2007) investigated the inventory of energy consumption of power generation, as well as the emissions of gaseous pollutants, liquid pollutants, and solid wastes. Yuan (2006) worked out the inventories of primary energy in China, including the energy consumption and environmental emissions involved in the extraction process of coal, crude oil and natural gas, and compiled the inventories from "cradle to gate" of several major downstream products derived from coal and crude oil, such as clean coal, coke, gas, petrol, diesel oil, and fuel oil.

\subsection{LCA in the materials industry}

With respect to the case study of specific materials in China, there are a large number of useful research and exploration activities. Zhou et al. (2006) investigated over 70 major iron and steel manufacturing plants in China to establish LCI datasets. The data scope covers the life cycle stages ranging from "cradle to gate", representing the environmental load of enterprises in different regions and with different levels of technology. Gao et al. (2009a, b, c) conducted a cradle-togate LCA to analyze greenhouse gas (GHG) emissions based on statistic data of the Chinese aluminum industry. The reduction potential of the GHG emissions for alumina and aluminum production was also estimated. Liao et al. (2012) offered a comprehensive comparison of the similarities and differences of seven resource indicators (including four thermodynamics-based indicators and three other indicators e.g. eco-indicator 99) and testing them in a case study on titanium produced in Panzhihua City, in southwest China. Gao et al. (2009a, b, c) investigated the accumulative environmental performances of magnesium production according to the actual situation of the Chinese magnesium industry; the LCA case study was performed on three different fuel use scenarios from coal as the overall fuel to two kinds of gaseous fuels: producer gas and coke oven gas.

Furthermore, the accumulated fundamental data and case studies of LCA have covered a wide range of areas in the 
Chinese materials industry, including pyrometallurgical and hydrometallurgical processes of copper production (Jiang et al. 2006), the smelting process in typical lead and zinc plants (Xiao et al. 2003), several kinds of macromolecule materials (Chen et al. 2004), glass (Chen 2007), biodegradable plastics (Meng 2010), and so on. All of this research plays a positive role in the improvement of the LCA database and its application in the materials industry.

\subsection{LCA in construction and related industries}

Chen et al. (2005) performed LCA and material flow analysis to study environmental impact caused by cement production in Beijing. They suggested initiating the 2008 Beijing's cement industry layout adjustment program under the premise that guarantees both the cement demands of Olympic construction and environmental protection requirements. While keeping the cement output basically unchanged, through (1) layout adjustment, (2) a combined approach, and (3) technological upgrading, the emission of air pollutants, including soot, fumes, and sulfur dioxide were decreased by 50,11 , and $2 \%$, respectively, compared to 2001 .

$\mathrm{Wu}$ et al. (2012) performed a process-based LCA to identify and quantify the energy consumption and $\mathrm{CO}_{2}$ emission from office buildings in China, then determined the significant environmental aspects that contributed the most to the overall impact. Based on the results of the study, some environmental improvements aimed at reducing energy consumption and $\mathrm{CO}_{2}$ emissions throughout the life cycle of the building were provided. Gong et al. (2012) analyzed the environmental impacts produced by three types of construction structures of multistory and multiresidential civilian buildings in Beijing, including (1) concrete framework construction, (2) light gauge steel framework construction, and (3) wood framework construction (WFC), during the stages of building materials production, construction, and use. Through the calculation of characteristic indicators of 11 types of environmental impacts as well as uncertainty and sensitivity analysis, the results showed WFC offers very obvious advantages because it ranked lowest in eight environmental impact categories, especially in climate change, radiation effects, ozone depletion, and land resource damage, all of which are closely related to human survival and well-being.

\subsection{LCA in other areas}

Last but not least, LCA practice was also initiated in many other areas and published in the International Journal of LCA: Yuan et al. (2013) evaluated the life-cycle environmental impacts of the textile-dyeing industry and identified key processes for mitigating life cycle environmental impacts; Xie et al. (2013) estimated the environmental impact of commonly used treatment of composite packaging waste to determine an optimal waste management strategy and design new separating and recycling technology for composite packaging; Hong et al. (Hong and Li 2012) carried out LCAs to estimate the environmental effects of pentachloroaniline biodechlorination under acidogenic/methanogenic conditions through laboratory scale experiments; Song et al. (2013) performed LCAs to investigate the environmental performance of PCs in Macau. We would like to encourage Chinese authors to submit their research results to future issues of this journal.

\section{Outlook}

As a quantitative tool, LCA aims at making a comprehensive assessment of the environmental impacts of products and services in a life cycle perspective, which has played an important role in many areas in China, including ecodesign, cleaner production, decision making, and so on. The review presented in this paper indicates several areas where the development has been active during the last decade, from regional methodology research, LCA databases and tools, to some typical case studies. In general, the application of LCA in China is still limited, and there is a wide gap between evaluation results and the anticipated criteria. LCA research needs to be continuously improved mainly in the following areas:

- Lack of data is still a common problem in current LCA practice in China, thus, the database needs be expanded and improved continuously.

- Cooperation between academia, research institutions, and industry from different areas of LCA practice and LCI data sharing and exchange is very important.

- Lack of regional methodology and related characterization factors in most of impact category (e.g. water, acidification, etc.), a national LCA methodology system needs to be established.

- Lack of uncertainty and sensitivity analysis for LCA results and methodology;

- Most LCAs have been performed by government and academic institutions, while recognition and interest from industries is lacking.

- Most research focuses on analysis of current environmental state of materials or products; however, methodology and related practice for predicting environmental impact (e.g., ecodesign) is also needed.

Although the research of LCA methods and its application are still needed to make an in-depth investigation in China, it has been accepted by the government and the public, and it has made great progress in recent years. LCA has been considered to be an effective tool to provide scientific decision making and technical guidance in many areas for the achievement of the target of energy-saving and emission-reducing. 
We can definitely expect more and more important activities in the field of Chinese LCA in the next couple of years.

Acknowledgments I would like to extend my sincere appreciation to my colleagues in the Center of National Materials life cycle assessment (CNMLCA) at Beijing University of Technology (BJUT) for their suggestions and comments on this paper based on their research experience in related areas of LCA: Associate Prof. Dr. Gao Feng (metallic material processes environment impact analysis); Prof. Dr. Gong Xianzheng (LCA database and data quality analysis), Dr. Liu Yu (regional LCIA methodology research), Prof. Dr. Cui Suping (ecobuilding materials development and related environmental issue analysis), Prof. Wang Zhihong (ecodesign theory and green manufacture technology), Prof. Zuo Tieyong (materials environmental issue), as well as $\mathrm{PhD}$ candidate Sun Boxue (Exergy-based LCA research) and Chen Wenjuan (environmental footprint analysis).

\section{References}

Chen H, Hao WCH, Shi F et al (2004) Life cycle assessment of several typical macromolecular materials. Acta Sci Circ 24(3):545-549 (in Chinese)

Chen WJ (2007) The study on life cycle assessment of flat glass production. Beijing University of Technology, Dissertation of Master's Degree (in Chinese)

Chen XQ, Guo YQ, Cui SP et al (2005) Material-energy metabolism and environmental implications of cement industry in Beijing. Resour Sci 27(5):40-46 (in Chinese)

Di XH, Nie ZR, Yuan BR et al (2007) Life cycle inventory for electricity generation in China. Int J Life Cycle Assess 12(4):217-224

Gao F, Nie ZR, Wang ZHH et al (2009a) Characterization and normalization factors of abiotic resource depletion for life cycle impact assessment in China. Sci China Ser E 52(1):215-222

Gao F, Nie ZR, Wang ZHH et al (2009b) Greenhouse gas emissions and reduction potential of primary aluminum production in China. Sci China Ser E 52(8):2161-2166

Gao F, Nie ZR, Wang ZHH et al (2009c) Life cycle assessment of primary magnesium production using the Pidgeon process in China. Int J Life Cycle Assess 14(5):480-489

Gong XZH (2006) Basic database researches for the life cycle assessment of materials. Beijing University of Technology, Dissertation of Doctor's Degree (in Chinese)

Gong XZH, Nie ZR, Wang ZHH et al (2006) Research and development of Chinese LCA database and LCA software. Rare Metals 25:101104 (Spec. Issue)
Gong XZH, Nie ZR, Wang ZHH et al (2012) Life cycle energy consumption and carbon dioxide emission of residential building designs in Beijing. J Ind Ecol 16(4):576-587

Hong JL, Li XZH (2012) Life cycle assessment comparison of substrates for the bioremediation of pentachloroaniline under acidogenic/methanogenic conditions. Int $\mathrm{J}$ Life Cycle Assess 17:79-88

Jiang JL, Dai JF, Feng WJ et al (2006) Life cycle assessment of metallic copper produced by the pyrometallurgical and hydrometallurgical processes. J Lanzhou Univ Technol 32(1):19-21 (in Chinese)

Li GQ, Nie ZR, Zhou HM et al (2002) An accumulative model for the comparative life cycle assessment case study: iron and steel process. Int J Life Cycle Assess 7(4):225-229

Liao WJ, Heijungs R, Huppes G (2012) Thermodynamic resource indicators in LCA: a case study on the titania produced in Panzhihua city, southwest China. Int J Life Cycle Assess 17:951-961

Liu Y, Gong XZH, Wang ZHH (2009) Multiple imputation for missing data in life cycle inventory. Mater Sci Forum 610-613:21-27

Liu Y, Nie ZR, Sun BX et al (2010) Development of Chinese characterization factors for land use in life cycle impact assessment. Sci China Ser E 53(6):1483-1488

Meng XC (2010) Life cycle assessment of polycarbonate and polylactic acid. Beijing University of Technology, Dissertation of Master's Degree (in Chinese)

Nie ZR, Di XH, Li GQ (2001) Material life cycle assessment in China. Int J Life Cycle Assess 6(1):47-48

Song QB, Wang ZSH, Li JH et al (2013) Life cycle assessment of desktop PCs in Macau. Int J Life Cycle Assess 18:553-566

Wu HJ, Yuan ZW, Zhang L et al (2012) Life cycle energy consumption and $\mathrm{CO}_{2}$ emission of an office building in China. Int $\mathrm{J}$ Life Cycle Assess 17:105-118

Xiao X, Xiao SW, Guo XY et al (2003) LCA Case study of zinc hydro and pyrometallurgical process in China. Int J Life Cycle Assess 8(3):151-155

Xie MH, Qiao Q, Sun QH et al (2013) Life cycle assessment of composite packaging waste management - a Chinese case study on aseptic packaging. Int J Life Cycle Assess 18:626-635

Yuan BR (2006) Measurement method for sustainable development of chemical industry and its application. Beijing University of Technology, Dissertation of Doctor's Degree (in Chinese)

Yuan ZW, Zhu YN, Jun KSH et al (2013) Life cycle assessment of continuous pad dyeing technology for cotton fabrics. Int J Life Cycle Assess 18:659-672

Zhou HM, Wang TM, Hao WCH et al (2006) Analyses of environmental impact assessment on the development model of circulation economy in Chinese steel industry. International Materials Research Conference (Beijing), pp 24-30 